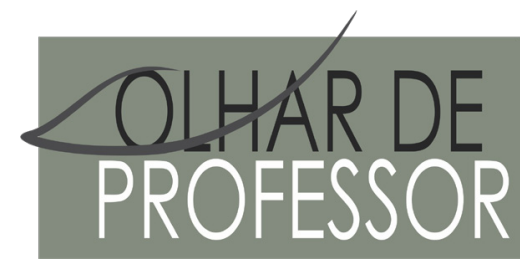

DOI: 10.5212/OLHARPROFR.v.23.2020.16175.209209226867.0616

\title{
EDUCAÇÃO NO ENSINO SUPERIOR EM TEMPOS DE PANDEMIA
}

EDUCATION IN HIGHER EDUCATION IN PANDEMIC TIMES

EDUCACIÓN EN LA ENSEÑANZA SUPERIOR EN TIEMPOS DE PANDEMIA

BRUNO RAFAEL SANTOS DE CERQUEIRA*

\begin{abstract}
Resumo: Em meio à pandemia de COVID-19, as Universidades Federais brasileiras vêm buscando uma solução para o ensino não presencial. A Universidade Federal do ABC foi uma das primeiras instituições a implementar um regime remoto de ensino. Assim sendo, o objetivo deste relato de experiência é refletir sobre esse processo de implementação como docente do Ensino Superior. Durante a disciplina, ministrada de forma não presencial, três elementos surgiram como obstáculos: a baixa interação, o tempo e as questões socioemocionais. Esses entraves tiveram grande influência no andamento do trabalho, de modo que fizeram emergir aspectos que pontuo como aprendizados para as propostas de ensino que estão sendo elaboradas em tempos de pandemia, a saber: a garantia de inclusão dos alunos, o suporte psicológico à comunidade universitária, a expansão das disciplinas para além dos conteúdos conceituais e o oferecimento de tempo suficiente para a elaboração de propostas que garantam a qualidade de ensino para todos.
\end{abstract}

Palavras-chave: Ensino remoto. Educação Superior. Política educacional.

Abstract: Amid the COVID-19 pandemic, the Brazilian Federal Universities have been looking for a solution for non-classroom teaching. The Federal University of $A B C$ was one of the first institutions to implement a remote teaching regime. Thus, the purpose of this experience report is to reflect about this implementation process as a Higher Education professor. During the discipline, given in a non-face-to-face manner, three elements emerged as obstacles: low interaction, time, and socio-emotional issues. These barriers had a great influence on the progress of the work, so that aspects that I point out as learning for the teaching proposals that are being developed in pandemic times emerge, namely: the guarantee of inclusion of students, psychological support to the university community , the expansion of the disciplines beyond the conceptual contents and the provision of sufficient time for the elaboration of proposals that guarantee the quality of teaching for all.

Keywords: Remote teaching. Higher Education. Education policy.

Resumen: En medio de la pandemia de COVID-19, las Universidades Federales brasileñas han buscado una solución para la enseñanza no presencial. La Universidad Federal de ABC fue una de las primeras instituciones en implementar un régimen de enseñanza remota. Así, el objetivo de este relato de experiencia es reflexionar sobre este proceso de implementación como docente en Educación Superior. Durante la asignatura, impartida de forma no presencial, tres elementos surgieron como obstáculos: la baja interacción, el tiempo y las cuestiones socioemocionales. Estos aspectos tuvieron gran influencia en el progreso del trabajo, por lo que hicieron surgir aspectos que destaco como aprendizajes para las propuestas de enseñanza que están siendo elaboradas en tiempos de pandemia, son: la garantía de inclusión de los alumnos, el apoyo psicológico a la comunidad universitaria , la expansión de las asignaturas más allá de los contenidos conceptuales y el ofrecimiento de tiempo suficiente para la elaboración de propuestas que garanticen la calidad de la enseñanza para todos.

Palabras-clave: Enseñanza remota. Enseñanza Superior. Política educativa.

\footnotetext{
* Doutor em Ensino de Ciências pelo Programa de Pós-Graduação Interunidades em Ensino de Ciências da Universidade de São Paulo (USP). Professor adjunto do Centro de Ciências Naturais e Humanas da Universidade Federal do ABC (UFABC). E-mail: bruno.cerqueira@ufabc.edu.br. ORCID: https://orcid.org/0000-0002-2625-9788
} 


\section{INTRODUÇÃO}

No dia 18 de março de 2020, em meio ao início da pandemia de COVID-19, foi publicada, no Diário Oficial da União, a Portaria No 343, aprovada no dia 17 de março de 2020 pelo Ministério da Educação (MEC). Tal documento autorizou a substituição das aulas dos cursos presenciais do Ensino Superior por meios remotos de ensino durante a pandemia de COVID-19. A Portaria delega às instituições a disponibilização de plataformas digitais para acompanhamento das disciplinas pelos alunos, bem como autoriza a suspensão de aulas com posterior substituição, caso as Universidades façam essa opção (BRASIL, 2020). Nesse primeiro momento, fica claro que Universidades Federais deveriam, sozinhas, com estruturas que já sofrem com baixos investimentos há anos, enfrentar a educação em tempos de COVID-19.

A partir da Portaria $N^{0} 343 / 2020$, boa parte das Universidade Federais brasileiras procederam com a suspensão de suas aulas, começando uma intensa mobilização e debates sobre como essas instituições deveriam atuar durante a crise sanitária, especialmente na questão do ensino. Por volta de dois meses depois, seis das 69 Universidades brasileiras iniciaram a retomada de suas aulas não presenciais, são elas: Universidade Federal do ABC (UFABC), Universidade Federal do Ceará (UFC), Universidade Federal da Fronteira Sul (UFFS), Universidade Federal de Mato Grosso do Sul (UFMS), Universidade Federal de Santa Maria (UFSM) e Universidade Federal de Itajubá (UNIFEI). Além dessas, duas outras adotaram arranjos parciais, Universidade Federal do Acre e Universidade Federal de São Carlos.

Por mais que os noticiários e alas do governo façam transparecer que as demais instituições de ensino estão paradas, não se pode reforçar tais inverdades, uma vez que existem outros elementos do tripé universitário que permanecem atuantes, como a pesquisa e a extensão, as quais vêm contribuindo imensamente com iniciativas que buscam minimizar o impacto do novo coronavírus. Além deles, devemos citar os setores administrativos que continuam ativos e que gerem diversos processos universitários essenciais. É importante ressaltar, também, que as demais instituições estão em constante busca por alternativas para a retomada do ensino, de modo que se mantenha a qualidade que é marca do Ensino Superior brasileiro.

Nesse contexto, muito se tem questionado sobre a eficácia da Educação a Distância (EAD), ou sobre a capacidade de interação promovida por essa modalidade de ensino. Contudo, é fundamental enfatizar que tais questionamentos, no atual cenário, não são adequados, pois o que as Universidades Federais brasileiras estão buscando não se trata de EAD - modalidade de ensino, reconhecida legalmente no Brasil na década de 1990, por meio da Lei de Diretrizes e Bases da Educação (LDB) - Lei No 9.394, de 20 de dezembro de 1996, do Ministério da Educação. A EAD é baseada em características próprias e exige a presença de alguns aspectos importantes:

A distância física entre professores e alunos, a comunicação com o uso da mídia, são inovações trazidas pela EAD que se constituem num desafio para as instituições de ensino. Exigem investimentos em tecnologia avançada para a mediação e ao mesmo tempo mudança na cultura dos professores e alunos que tem como parâmetro o modelo pedagógico presencial, caracterizado pela presença física de professores e alunos num mesmo tempo e espaço (MUGNOL, 2009, p. 338).

Tampouco podemos falar em uma mera transposição das aulas da forma presencial para alguma plataforma digital, pois incorreríamos em sérios problemas pedagógicos. Do que estamos ou deveríamos estar falando afinal? Deveríamos estar falando de uma proposta alternativa que levasse em consideração o momento que vivemos, que adaptasse os seus objetivos às questões suscitadas por uma crise sanitária e que se preocupasse com as especificidades da sua comunidade universitária.

Nesse contexto, este relato tem como objetivo apresentar e refletir, na qualidade de docente do Ensino Superior, sobre como ocorreu a decisão institucional da Universidade Federal do ABC, localizada na cidade de Santo André, estado de São Paulo, por manter parte das disciplinas por meio da modalidade remota e o que aprendemos sobre a educação em tempos de pandemia após a finalização do primeiro quadrimestre do calendário acadêmico.

Com este texto, o objetivo é fomentar os debates sobre o tema nas demais instituições e evidenciar os obstáculos que enfrentamos nesse período na UFABC. Desse modo, este relato está estruturado em mais três seções: o contexto da UFABC, o plano de estudos continuado emergencial adotado pela instituição 
e reflexões sobre essa estratégia. Este relato busca considerar os impactos das decisões tomadas nos processos de ensino e de aprendizagem e aspectos que podem ser reformulados para a continuidade do ensino em nossas Universidades.

\section{O CONTEXTO DA UNIVERSIDADE FEDERAL DO ABC}

O contexto da Universidade Federal do ABC é muito importante para que se entenda a implementação do plano de ensino remoto da instituição. Sendo uma das mais jovens Universidades Federais, a UFABC foi fundada no ano de 2005 e, hoje, conta com quase 20.000 alunos. Seu projeto inovador conta com bases interdisciplinares e estímulo à autonomia dos alunos. Localizada na região metropolitana de São Paulo, a instituição tem características que a diferem de outras Universidades.

O primeiro ponto a ser ressaltado está relacionado ao nosso calendário acadêmico, o qual é orientado por quadrimestre. Assim sendo, para 2020, a organização anual estava programada conforme o esquema do Quadro 1 a seguir.

QUADRO 1: CALENDÁRIO ACADÊMICO DE २०२० DA UNIVERSIDADE FEDERAL DO ABC

\begin{tabular}{|c|c|c|c|c|c|c|c|}
\hline \multicolumn{2}{|c|}{$1^{\circ}$ Quadrimestre } & Recesso & \multicolumn{2}{|c|}{$2^{\circ}$ Quadrimestre } & Recesso & \multicolumn{2}{|c|}{$3^{\circ}$ Quadrimestre } \\
\hline Início & Fim & $1631 / 05$ & Início & Fim & 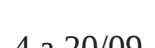 & Início & Fim \\
\hline $10 / 02$ & $15 / 05$ & $10 \mathrm{~d} 31 / 0 \mathrm{~J}$ & $01 / 06$ & 03/09 & $4 \mathrm{~d} 20 / 09$ & $21 / 09$ & $18 / 12$ \\
\hline
\end{tabular}

FONTE: OAUTOR.

Contudo, a suspensão das aulas, em decorrência da pandemia, ocorreu no dia 13 de março de 2019, período em que por volta de $40 \%$ do quadrimestre havia sido cumprido. Esse cenário é bem diferente de outras instituições que seguem o regime semestral e que, portanto, iniciam suas aulas mais tardiamente. Um aspecto bastante relevante é que já havia contato entre os alunos e os docentes das disciplinas em curso, o que gerou disposição para que os estudos continuassem.

Uma outra característica diz respeito ao ingresso de novos alunos. Na UFABC, esse processo ocorre juntamente ao início do segundo quadrimestre, isso implica dizer que o quadro de alunos no momento da interrupção das aulas era formado apenas por discentes que já tinham contato com a Universidade e, portanto, já estavam sociabilizados com a rotina de estudos no Ensino Superior. Foi nesse cenário e motivados pela continuidade do trabalho iniciado que foi pensando um plano para a continuidade dos estudos.

\section{O PLANO DE ESTUDOS CONTINUADO EMERGENCIAL: REFLEXÕES SOBRE A EDUCAÇ̄̃̃ EM TEMPOS DE PANDEMIA}

Saviani (1986) afirma que o ensino que não levar em consideração o meio social e histórico do homem e, ao mesmo tempo, a contribuição do conhecimento científico tem poucas condições de eficácia e, certamente, se tornará uma forma de alienação. Nesse sentido, como materializar o momento que vivemos nas propostas de continuidade do ensino nas Universidades?

A proposta elaborada na UFABC foi intitulada "Plano de estudos continuado emergencial (ECE)", resultado do período de discussão institucional que envolveu vários setores da comunidade universitária, entre os dias 13 de março (suspensão das aulas) e 20 de abril (retomada remota das disciplinas). Foram organizados debates e instaurados grupos de trabalhos para contemplar as seguintes temáticas: a inclusão dos alunos, o uso de plataformas digitais e a possibilidade de continuidade das disciplinas.

Em relação à inclusão e ao acesso dos alunos aos meios digitais, pouco avançamos antes do início do ensino remoto, pois foram garantidas apenas a manutenção dos auxílios financeiros aos alunos de baixa renda pela Pró-Reitoria de Assuntos Comunitários e aberta a possibilidade de trancamento de disciplinas no quadrimestre. Infelizmente, não foi considerado que era necessário criar esforços para atendimento aos alunos antes que se iniciasse qualquer proposta de ensino. 
Quanto ao uso de Plataformas digitais, foi dado ao professor a possibilidade de escolha da plataforma a ser utilizada. Nesse quesito, não foram pensados cursos ou formação para a comunidade universitária para familiarização em relação às ferramentas digitais necessárias ao ensino remoto. O quadro de disciplinas a serem continuadas foi definido a partir da escolha dos docentes. Desse modo, aqueles que optassem por não dar continuidade de modo remoto implicaria o fechamento da turma e, caso fosse possível, a transferência de alunos entre turmas.

Apesar de ser apresentado de forma resumida, o ECE foi alvo de divergências, principalmente no quesito de inclusão de parcela de alunos sem acesso aos meios digitais e na questão de preparação dos docentes para atuar nessa modalidade de ensino. Podemos voltar à afirmação de Saviani (1996) e questionar: Quanto essa proposta é capaz de considerar o momento que estamos vivendo?

\section{ALGUMAS CONSIDERAÇ̃̃ES SOBRE O QUE APRENDEMOS COM O ECE}

Este relato sobre as aprendizagens a partir do ECE é advindo da minha atuação docente junto a uma disciplina ministrada a 40 alunos da Graduação e dos debates que estão sendo conduzidos sobre a avaliação dessa experiência na Universidade. Coincidentemente, a disciplina que ministrei no quadrimestre finalizado via ECE chama-se "Desenvolvimento e Aprendizagem", na qual discutimos sobre teorias de desenvolvimento e de aprendizagem. Não poderia ter momento mais oportuno, uma vez que a pergunta mais feita neste momento na educação é: Como ensinar e aprender a distância?

Com a implementação do ECE e com a minha adesão, foi solicitado um novo plano de ensino para a continuidade da disciplina. O objetivo principal do documento era que a disciplina fosse repensada para um esquema não presencial. Nesse processo, diversas questões emergiram: Quais conteúdos devem ser priorizados em um momento de pandemia? Qual o objetivo da formação que oferecemos aos estudantes? Quais teorias da aprendizagem poderiam nos guiar nesse momento? Confesso que essas perguntas continuam abertas e outras surgiram ao longo do caminho.

A disciplina foi adaptada a partir da supressão de alguns temas para adequação ao tempo característico de um ensino não presencial. Isso também se aplicou às atividades solicitadas, as quais foram adequadas à modalidade assíncrona, conforme solicitação da Universidade, a fim de possibilitar chances de acesso aos estudantes. No decorrer da disciplina, três elementos surgiram como obstáculos: a baixa interação, o tempo e as questões socioemocionais.

Para uma disciplina estruturada a partir de uma perspectiva sociointeracionista, foi difícil restringi-la a uma plataforma quase inerte, conversas, debates, olhares, argumentação e outros aspectos se perdem em meio aos cliques, às páginas e aos links. A baixa troca entre os colegas não conseguiu ser resolvida com fóruns, videoconferências e conversas em grupos nas redes sociais. Importante lembrar que não estou falando de uma educação estruturada para ser a distância, tampouco em docentes e alunos adaptados a essa modalidade de ensino.

A distância física pode ser um fator preponderante para uma lacuna no processo de comunicação, criando espaços para potenciais compreensões errôneas entre professores e alunos, que necessita ser por recursos tecnológicos de interação e constantes conversas (MOORE; KEARSLEY, 2008). O uso dos recursos tecnológicos deve ser apoiado em uma filosofia de aprendizagem que embase as escolhas tecnológicas do docente, de modo a propiciar momentos que valorizem o compartilhamento, o debate, a construção coletiva do conhecimento e o respeito à diferença, conforme ressaltado por Sanchez (2008).

O tempo para reflexão no ensino remoto entrelaça-se às inúmeras tarefas solicitadas pelos diversos professores do grupo de disciplinas cursadas pelos alunos. Nesse sentido, aflora-se um problema coletivo que só é maximizado pelo momento que passamos. É possível somente transpor uma disciplina do ensino presencial para o remoto? A resposta, apesar de óbvia, ainda não é compreendida por todos.

Muitos docentes e alunos não entendem esse ponto e reforçam a crença na manutenção do quadro de disciplinas planejadas e da sua estrutura carregada por uma carga de conteúdos e de tarefas pensados para o tempo presencial. Enquanto isso, nossos colegas que já pesquisam e ensinam na modalidade EAD apontam, há anos, que o tempo de aprendizagem no ensino a distância é diferente. Belloli (2008) ressalta que há, no Ensino Superior, dificuldades que atrasam as mudanças no ensino, especialmente uma tendência 
docente de resistência à incorporação dos recursos tecnológicos em sua prática, o que bloqueia a potencialidade desses recursos. Isso nos leva a refletir sobre como as propostas que estão sendo desenvolvidas preveem a formação de seu corpo docente para atuar nesse novo projeto de ensino.

Todas essas questões implicam o terceiro ponto, as questões socioemocionais. Vemos que plataformas digitais, aplicativos, computadores e pacotes de internet não resolverão aspectos que são inerentes aos tempos de pandemia. Alunos arriscando suas vidas porque precisam trabalhar presencialmente, professores sobrecarregados e sentindo-se perdidos em meio a novas situações de ensino, e a reclusão social que nos inunda em uma mistura de angústia, ansiedade e sofrimento e, novamente, as perguntas: $\mathrm{O}$ que podemos aprender e ensinar em meio à pandemia? Qual o papel dos professores das Universidades públicas brasileiras?

No atual momento, de balanço dessa primeira experiência e preparação para o próximo quadrimestre, temos alguns pontos de convergência em nossa comunidade universitária. Não podemos aceitar que alunos fiquem impossibilitados de continuar suas aulas por falta de acesso. Entendemos que há pessoas em situação de vulnerabilidade e que nossas ações para a construção da justiça social no âmbito da Universidade deve ser o motor de qualquer proposta que almeje o ensino. Também não podemos aceitar que a comunidade universitária adoeça emocionalmente; assim, o momento que passamos necessita de cuidados, e as disciplinas devem contribuir para um ambiente de trocas e não de punições psicológicas. Além disso, aprendemos que não tem como prezar pela qualidade sem estrutura, sem formação e sem união institucional. O sucateamento que as Universidades vêm sofrendo se agravou ainda mais com essa crise e põe em evidência o quanto um (des)governo pode nos desmobilizar.

Para concluir, as atividades universitárias não precisam girar em torno do conteúdo disciplinar para que mantenhamos o vínculo e o cuidado com o corpo estudantil. Dessa forma, qualquer saída para o ensino em tempos de pandemia deve considerar as especificidades do momento que vivemos, e as propostas devem atender os anseios de sua comunidade, para que tenha sentido em meio ao caos.

Entendo que essas propostas devem ser inclusivas e democráticas, e as Universidades Federais brasileiras não podem perder de vista seu papel como instituição científica comprometida com a sociedade. É imprescindível que cada Universidade tenha o tempo suficiente para deliberar sobre a melhor forma de agir, de modo a garantir um planejamento que compreenda a preparação estrutural, de formação pessoal e da inclusão. Sem esse tempo necessário, arriscaremos um bem importante que é a qualidade do Ensino Superior brasileiro, gratuito e para todos.

\section{REFERÊNCIAS}

BELLONI, M. L. Educação a distância. 5.ed. Campinas: Autores Associados, 2008.

BRASIL. Lei No 9.394, de 20 de dezembro de 1996. Estabelece as diretrizes e bases da educação nacional. Diário Oficial da União: seção 1, Brasília, DF, n. 248, p. 27833-27841, 23 dez. 1996.

BRASIL. Portaria No 343, de 17 de março de 2020. Dispõe sobre a substituição das aulas presenciais por aulas em meios digitais enquanto durar a situação de pandemia do Novo Coronavírus - COVID-19. Diário Oficial da União: seção 1, Brasília, DF, n. 53, p. 39, 18 mar. 2020.

MOORE, M.; KEARSLEY, G. Educação a Distância: uma visão integrada. São Paulo: Cengage Learning, 2008.

MUGNOL, M. A Educação a Distância no Brasil: conceitos e fundamentos. Revista Diálogo

Educacional, Curitiba, v. 9, n. 27, p. 335-349, 2009. Disponível em: http://dx.doi.org/10.7213/rde. v9i27.3589 Acesso em 20 de ago. de 2020.

SANCHEZ, F. (Coord.). Anuário Brasileiro Estatístico de Educação Aberta e a Distância (AbraEAD). 4. ed. São Paulo: Instituto Monitor, 2008.

SAVIANI, D. Ensino público e algumas falas sobre universidade. São Paulo: Cortez, 1986. 